\title{
The Research of Computer Technology Application in Enterprise Financial Management
}

\author{
Na Xu \\ Zaozhuang University, Zaozhuang, Shandong Province, China \\ xuyunna333@126.com
}

Keywords: computer technology; enterprise finance; management

\begin{abstract}
Computer network technology, as an essential means for the financial management of enterprises, has become more widely used. The application of computer technology has improved the financial work level of enterprises, improved the working environment, and effectively solved the problems existing in corporate financial work. This paper first elaborates the problems existing in the financial management of Chinese enterprises, then analyzes the role of computer technology in financial work, and finally puts forward countermeasures and measures for the application of computers in financial management with certain practical significance.
\end{abstract}

\section{Introduction}

In the market economy environment, the enterprise competition is becoming increasingly fierce. Financial management plays a central role in the management of enterprises. The problems are increasingly highlighted and face enormous challenges. With the application of computer technology in corporate financial management, its management environment and methods have undergone tremendous changes. Many problems have been effectively resolved, which has improved the company's competitiveness [1]. It can be seen that the application of computer technology in enterprise financial management has achieved certain results. In order to meet the higher financial work needs of enterprises and at the same time continue to adapt to the social and economic development, it is still necessary to further improve them.

\section{Status Quo of Chinese Enterprises' Financial Management}

Strengthening the financial management of enterprises is an important issue that companies face at present, but due to the influence of traditional concepts, concepts, and other factors, their financial work still faces some problems.

\subsection{Confusing money management}

Enterprise fund management is the main content of financial management, and it is also a key issue for managers. Some enterprises' use and management funds are not standardized, especially for companies that have separate accounting for the branch companies and the head office, resulting in long management of funds, inadequate supervision of funds, serious capital deposits and blind investment, and accelerating the loss of funds [1]. Reduce the economic benefits of the company.

\subsection{Lack of financial supervision}

At present, the company's financial supervision system is still not perfect, and some enterprises have insufficient efforts in the implementation of the supervision work, which increases the company's financial risks [2]. Some companies, due to severe distortion of financial information and inadequate supervision mechanisms, cannot play the role of financial supervision and ultimately lead to the failure of corporate investment decisions.

\subsection{The unguaranteed authenticity of financial information}

Due to various reasons such as incorrect vouchers and accounting confusion, the financial 
information of the company is asymmetric, which not only affects the financial management of the company, but also hinders the normal production and business activities of the company. Some financial personnel are not serious about their work attitudes, their sense of responsibility is not strong, and they are often flawed [1]. In serious cases, they even make false accounting reports, leading to distorted corporate financial information. At the same time, communication between various departments is not smooth and financial information is lagging, which has a direct impact on corporate decision-making.

\section{The Effect of Computer Technology Application in Financial Management}

\subsection{Standardize financial fundamentals and accelerate accounting}

Computerized accounting enables computers to automatically carry out accounting and other tasks, and treats duplicated businesses. Accounting vouchers can be generated automatically. This also ensures the accuracy of accounting information while improving its accuracy. The computer completed the accounting treatment and standardized the basic work of financial management [2]. All kinds of data vouchers are input according to subjects, the format is not uniform, and the problem of non-standard accounting is fundamentally solved, which reduces the error rate of manual operations and improves the quality of accounting. A large amount of financial information was collected and analyzed in a timely manner. After uploading, the financial information was shared, the asymmetrical financial information was improved, and the quality of financial information was guaranteed. At the same time, the quickness and convenience of data query are improved, the financial personnel can obtain the required data in time, make reasonable decisions after analysis, and improve work efficiency and quality [2]. Financial accounting can be carried out at the same time as day-to-day operations of enterprises, and the application of computers has improved the lag in accounting work. Although the content of accounting and the types of reports have increased, but in the computer system, the financial accounting procedure is simple, and the computer can set up reference points for all aspects of financial accounting, thus effectively controlling the financial work and greatly improving the accounting.

\subsection{Improve the internal control system}

The implementation of accounting computerization enables all departments of the company to operate in a uniform manner in the system module. In order to ensure the smooth implementation of the operation, the company has established a corresponding degree of internal control to clarify the job responsibilities and regulate its operation process [3]. The computer guarantees the real-time monitoring of financial internal control and can report the status of internal control to financial personnel in a timely manner.

The application of computers has also increased the sharing of corporate accounting information, and has effectively controlled the logistics, information flow, and capital flow of the company. While managing financial information, financial managers can provide effective information, participate in major corporate decisions, and reduce the risks of the company. The internal control work runs through every link of the company's daily operations and production activities, and even achieves remote control [3]. Computer technology enables financial personnel to remotely monitor the financial status of the company through the Internet, manage funds through online settlement, and use it to conduct internal control and remote accounting.

\subsection{Improve the level of capital management work}

The use and circulation of funds is one of the core contents of the financial work. The introduction of computer technology has expanded the scope of corporate fund use, including online banking, electronic money, etc.; it has also brought about a certain speed while accelerating the speed of capital operation. Capital risk. In order to reduce risks and improve the safety of funds, many companies have realized centralized management of funds on a computer-based basis, effectively controlled the operation of funds, ensured the normal operation of corporate funds, and played a greater role in the 
use of funds [3]. The application of computers can help companies to conduct scientific analysis on the purchasing power of customers, reasonably determine credit limits, and ensure the recovery of receivables. At the same time, they can reasonably predict the flow and direction of funds and scientifically allocate funds. The computer improved the unified accounting work, reduced capital deposits, made the company's funds no longer manage long, balanced the use of funds, improved the efficiency of capital operations, and also reduced the risk of blind investment.

\subsection{Strengthen corporate budget management}

The computer provides a good technical platform for the company's budget management work. Each department can participate in the whole process of budget work, improve overall budget management, realize effective monitoring of the entire budget process, find problems in a timely manner, and identify corresponding improvement measures, Strengthen budget control and improve financial work [4]. At the same time, the application of the computer has realized the centralized management of financial information, can settle the expenses of the project under construction in time, make the control point move forward, and realize the effective monitoring of expense management and project management.

\subsection{Realize the real-time control of financial work}

The application of computer technology has made effective real-time control over financial costs, financial budgets, financial risks, and fund management, reflecting the real-time control of financial work. Computer technology can effectively control the entire process of preparation and implementation of financial budgets, guarantee the scientificity of forecasting, and provide basis for the customization and achievement of forecasting goals; when implementing forecasts, they can control the differences timely and ensure the smoothness of budgets [4]. Financial risk warning mechanisms have been strengthened. Real-time monitoring can effectively identify risks and issue early warnings in a timely manner so as to actively take measures to reduce risks and reduce the management costs of financial risks. The application of computers ensures the rapid accounting of business costs, so that the optimal cost control program can be obtained in the shortest time.

\subsection{Change the functions of financial management}

The application of computer technology makes the company's processes streamlined, and a large number of financial information is centralized by computers, improving the authenticity of financial information, reducing the intensity of manual labor and improving work efficiency. The focus of the work of some financial personnel has changed from the original affairs work to the control decision-making work, the functions of the financial work have been expanded, and the full participation of the financial personnel in the decision-making of the enterprise has been realized. With the change of the financial work environment and functions, the financial position of the company has also been adjusted accordingly. The financial personnel can only adapt to their new positions only by continuously upgrading their professional skills and computer knowledge [4]. The application of computer technology also strengthens the functions of decision-making and control of financial work. With the support of computer networks, it is easier and faster for enterprises to obtain financial data. The enterprise decision after risk assessment will be more reasonable and scientific; and the use of computers for decision-making control can discover timely. Correct problems and realize follow-up supervision of the decision-making process. The control effect is more obvious.

\section{Application of Computer Technology in Financial Management}

Although the enterprise management in the information age has changed the business process according to the new management requirements, the presentation mode still focuses on quarterly and annual financial statements. However, a single financial data indicator can no longer meet the requirements of business decision-making [5]. From a management point of view, since the financial statements are a reflection of business results, the business process has ended when the business data is converted into financial data responses. Isolated financial accounting cannot participate in the 
processing of the entire business process, and cannot function as a management and monitoring function. From the perspective of analysis, the indicators are single, and it is impossible to analyze the operating capabilities, development capabilities, and overall performance of the company. The value of intangible assets reflected by these indicators is often greater than that of tangible assets.

\subsection{To ensure the security of computer technology applications}

In order to ensure the security of financial data, it should provide a good environment for the use of computers. Based on the use of password protection, it should strengthen the law's propaganda and formulate relevant safety laws and regulations. Enterprises should establish a control mechanism, improve computer user rights management, backup data, and ensure the security of financial information [5].

When using financial software, it is necessary not only to consider the convenience and functional applicability of software operations, but also to pay attention to its confidentiality. With the development of economy, the requirements for financial software of enterprises are more stringent, and the depth and breadth of the software involved in the business are gradually increasing. The software selected by the enterprise should consider its secondary development capabilities to fully meet the needs of financial work.

\subsection{Software technology must be closely integrated with the actual business management}

The use of unified software to strengthen the unified management of corporate financial funds will help improve the authenticity of corporate financial information, help improve the transparency of corporate capital operations, help improve the management level of the entire enterprise, and accelerate integration with the international economy [6]. It can be seen that the development of software technology has always been inseparable from the enterprise, or that its roots are in the enterprise, the enterprise is the foothold for software development, and the enterprise's demand is the direction of software development. The promotion of financial management informationization by enterprises has provided sufficient market space for the development of China's software industry. The software company should take the initiative to strengthen the contact with the company, and continuously improve and update the software technology according to the actual needs of the enterprise management. Management requires software and software to be managed [6]. It is a good combination of the two to jointly research and develop a financial management information system that is in line with the actual situation of the company. It is an important task for us to promote the construction of financial management information for enterprises.

\subsection{Improve the quality of financial personnel and strengthen basic work}

The application of computer technology in financial work has caused great changes in the content of financial management, and the requirements for financial personnel have also been improved. It is not only necessary to master the financial professional knowledge and skills, but also to master the computer operation knowledge in order to be able to handle certain simple malfunction [7]. That can consider carrying out the computer knowledge training work, strengthening the knowledge and skills of some personnel, and being able to complete the computer daily maintenance, software application guidance, and data analysis work. In order for the role of the computer to be better utilized in the financial work, financial personnel should master modern management methods, continuously improve their work skills and qualities, and be excellent at their own work.

\subsection{Accelerate the application of computer technology in financial management}

First of all, actively promote the application of computer technology, computer technology can effectively monitor the use of funds in the financial work, can promote the financial management personnel to timely contact and master advanced financial concepts at home and abroad, thereby accelerating the process of informationization [7]. Secondly, to improve the internal information system of the company and to conduct comprehensive and timely management of the relevant financial work in all aspects of the company's business activities, the information system can reduce the probability of manual operation errors, and can achieve a better solution to the distortion of 
financial information. Actively promote companies to make the right investment decisions. Finally, computer technology has promoted the integration of corporate financial work and business work. This model has achieved the unification of business processes and internal information, improved the integration of corporate logistics, information flow, and capital flow, and improved the financial efficiency.

\subsection{Continue to optimize the information construction of financial management}

The financial management informationization of modern enterprises must be continuously optimized and improved. Internally, enterprises must work together and under the guidance of business objectives, fully understand the continuity of the financial management information system construction and in accordance with the principle of creativity and coordination, constantly improve the functions of the financial management information system, complete the financial management information system and other [5]. The excuse of the information system to achieve data sharing, and ultimately achieve continuous optimization, improve the level of management, and fully achieve the goal of financial management.

\subsection{Improvement the risk management information}

When an enterprise uses a computer to carry out financial work, it should periodically check and backup software and hardware equipment and financial information data, find effective measures to control the invocation and access of data, and strengthen the awareness of risk prevention [7]. At the same time, we must consider the cost-effectiveness and make reasonable use of computers. Recognizing that computers are only a means of financial work does not replace the company's management philosophy and culture.

\section{Summary}

The application of computer technology in financial work has effectively solved problems in the company's financial work, raised the level of financial work, and promoted the development of the company. However, due to factors such as the company's financial philosophy and technical level, the application of enterprise computers still faces many challenges. Enterprises should find reasonable measures to ensure their stable and lasting development.

\section{References}

[1] M.T. Li, Small business financial management, Shanghai: Shanghai University of Finance and Economics Press, 2004, pp.12-14.

[2] X.W. Meng, On enterprise financial management informatization, Modern economic information. 2010, vol.2, pp.14-17.

[3] D.Y. Wang Dong, Application of computer technology in corporate financial management, Information and Computers, 2010, vol.9, pp.76-79.

[4] X.H. Yin, Application of computer network technology in enterprise financial management, Chinese Business, 2010, vol.9, pp.7-9.

[5] X.Y. Jing, Information management of financial management, Science and Technology Innovation Guide, 2011, vol.2, pp.54-56.

[6] Zh.Q. Chen, Application of computer network technology in enterprise financial management, Enterprise Research, 2008, vol.11, pp.65-67.

[7] Y.X. Lou, Research on enterprise financial management informatization, Modern Economic Information, 2011, vol.3, pp.19-21. 